\title{
Procesos migratorios de ida e volta. Oralidade e transposición escrita nas me- morias dun militante antifranquista: David Álvarez Carballido. De Galicia a Arxentina (e viceversa) ${ }^{1}$
}

\author{
Mariela Sánchez ${ }^{2}$
}

Recibido: 9 de xullo de 2019 / Aceptado: 15 de febreiro de 2020

Resumo. Este artigo expón diferentes aspectos e cuestións teóricas vencelladas a un proceso de edición feito sobre a base dunha serie de entrevistas orais realizadas nos anos 90 por Antón Santamarina, a selección publicada en homenaxe a Xesús Alonso Montero e a reunión, por Anahí Almasia, no ano 2016, destas fontes que tiveron como protagonista a David Álvarez Carballido (A Fonsagrada, 1922-2017). O material obxecto de análise comprende a narración en lingua galega dunha historia persoal e familiar que involucra un marco referencial ilustrativo de avatares históricos e políticos fundamentais de Galicia e de Arxentina ao longo de gran parte do século XX, así como tamén aspectos de procesos migratorios e experiencias de represión e cárcere que se poden recoñecer noutras latitudes. Preténdese analizar as operacións de transposición en libro dos soportes ditos e as bases teóricas tidas en conta particularmente no proceso de edición no que participei.

Palabras chave: migración; memoria; narrativas; testemuño; oralidade; David Álvarez Carballido.

[es] Procesos migratorios de ida y vuelta. Oralidad y transposición escrita en las memorias de un militante antifranquista: David Álvarez Carballido. De Galicia a Argentina (y viceversa)

Resumen. Este artículo expone diferentes aspectos y problemáticas teóricas en relación con un proceso de edición llevado a cabo sobre la base de una serie de entrevistas orales realizadas en los años 90 por Antón Santamarina, la selección publicada en homenaje a Xesús Alonso Montero y la reunión, por Anahí Almasia, en 2016, de estas fuentes que nuclearon como protagonista a David Álvarez Carballido (A Fonsagrada, 1922-2017). El material objeto de análisis comprende la narración en lengua gallega de una historia personal/familiar que involucra un marco referencial ilustrativo de avatares históricos y políticos fundamentales de Galicia y de Argentina a lo largo de gran parte del siglo XX, así como también aspectos de procesos migratorios y experiencias de represión y encierro reconocibles en otras latitudes. Se pretende analizar las operaciones de transposición en libro de los soportes antedichos y las bases teóricas tenidas en cuenta en el proceso de edición en el que participé.

Palabras clave: migración; memoria; narrativas; testimonio; oralidad; David Álvarez Carballido.

[en] Roundtrip Migration Processes. Orality and Written Transposition in the Memoirs of an Anti-Franco Militant: David Álvarez Carballido. From Galicia to Argentina (and vice versa)

Abstract. This paper exposes different aspects and theoretical problematizations in relation to an editing process conducted on the basis of a series of oral interviews carried out in the 90s by Antón Santamarina, the selection published

Este traballo inscríbese nos proxectos de investigación "España y Argentina en diálogo. Literatura, cultura, memoria. 1940-2013” (PICT 2016-623), da Agencia Nacional de Promoción Científica y Tecnológica, dirixido por Raquel Macciuci, e no cal son parte do grupo responsable, e "Memoria de migración, experiencia bélica y exilio. España y Argentina: Representaciones literarias de y sobre mujeres en contextos de guerra, dictadura y destierro durante el siglo XX" (PID 11/H897), baixo a miña dirección e a codirección de Virginia Bonatto.

2 Instituto de Investigaciones en Humanidades y Ciencias Sociales (UNLP/CONICET), Facultad de Humanidades y Ciencias de la Educación, Universidad Nacional de La Plata (Argentina).

Correo-e: msanchez@fahce.unlp.edu.ar; https://orcid.org/0000-0002-7960-6261. 
in homage to Xesús Alonso Montero and the meeting, by Anahí Almasia, in 2016, from these sources that featured David Álvarez Carballido as the protagonist (A Fonsagrada, 1922-2017). The material under analysis includes the Galician-language narrative of a personal / family history that involves a referential framework illustrating the fundamental historical and political vicissitudes of Galicia and Argentina throughout most of the 20th century, as well as aspects of migratory processes and experiences of repression and confinement recognizable in other latitudes. I will analyze the book transposition operations of the aforementioned supports and the theoretical foundations taken into account in the editing process in which I participated.

Keywords: Migration; Memory; Narratives; Testimony; Orality; David Álvarez Carballido.

Sumario. 1. A palabra e a Historia, entre o mundo íntimo e o exercicio profesional. 2. "Permiso de existencia" ou eses libros que se queren facer un lugar. 3. As operacións de transposición e o xiro subxectivo. 4 . O persoal no colectivo. 5. Referencias bibliográficas.

Como citar: Sánchez, M. (2020): "Procesos migratorios de ida e volta. Oralidade e transposición escrita nas memorias dun militante antifranquista: David Álvarez Carballido. De Galicia a Arxentina (e viceversa)", en $M a-$ drygal. Revista de Estudios Gallegos 23 Núm. Especial, pp. 321-330.

\section{A palabra e a Historia, entre o mundo íntimo e o exercicio profesional}

O presente artigo consiste en expor diferentes aspectos e precaucións teóricas e metodolóxicas vencelladas a un proceso de edición feito sobre a base dunha serie de entrevistas orais do ano 1998 a cargo do filólogo da Universidade de Santiago de Compostela Antón Santamarina cun militante antifranquista, David Álvarez Carballido, comunista de base que tivo unha actividade constante en Galicia e na Arxentina, e a reunión deses materiais por un familiar da testemuña, Anahí Almasia -psicóloga e escritora- no ano 2016. Daquela, no 2016, eu fora convocada para facer a transposición que implicase que a base oral do testemuño resultase viable para a lectura, o que requiría considerar as desgravacións da oralidade e sometelas a unha dinámica de cotexo, posto que foran encaradas moito antes de que houbese unha coidadosa conciencia e teoría dabondo desenvolvida sobre Historia Oral, e as pasaxes que subsume a literariedade dun soporte cando migra a outro. Pero emerxeu ademais a condición de que a disposición da oralidade adoptase, nas páxinas escritas, a cadencia do plasmado para ser lido. As conversas de sobremesa, sostidas grazas ao profesionalismo dun filólogo en imbricada relación coa confianza que brindara o feito de tratarse dun achegado á súa contorna, ían ver necesariamente afectados unha serie de factores que non poden formar parte da escrita. Isto non debe ser visto como un déficit. Trátase -e iso é o fundamental- de linguaxes diversas, cada unha coas súas características e recursos. De xa non ser factible a recomposición e a reprodución dun clima de intimidade, o da cociña dunha casa galega, cos suxeitos presentes e preto uns dos outros, coa musicalidade das voces e das expresións familiares, co aroma dun café que viña perfumar a 'xestión das lembranzas', tiñamos que facer fronte ao desafío e non concentrarnos nas 'perdas' que a nova presentación impuña. Facía falta poñer en valor a transmisión desas vivencias que alumeaban non só a testemuña, senón tamén, e moi fundamentalmente, a moitísimos outros suxeitos e historias esquecidas ou non coñecidas desde este punto de vista.

Eses materiais, traballados durante 2016 e 2017, a dúas beiras entre Galicia e Arxentina, foi finalmente publicado en Galicia en 2018 pola editorial Alvarellos. A intención orixinal era que o protagonista coñecese o libro, xa que as entrevistas feitas vinte anos antes tiñan ese obxectivo, mais o proxecto quedara inconcluso e, neste 'coller azos' que tivo lugar case dúas décadas despois, non se chegou a tempo. Nado en San Martín de Suarna, A Fonsagrada, en 1922, conveciño da familia Santamarina -de feito outros membros, a muller e os fillos de Antón Santamarina, fixeron parte tamén das entrevistas-, David faleceu en 2017, moi pouco antes de que a súa sobriña e mais eu rematásemos o traballo de edición das súas memorias, que organizaba e literaturizaba a narración gardada durante todo ese tempo en once cintas que percorrían gran parte da historia do século XX, tanto de Galicia canto de Arxentina. El, de todos os xeitos, sabía que iso estaba en marcha, malia que non o chegase a ver concretado.

Pero, como xa deixei entrever coa alusión a outros suxeitos e outras historias, alén do caso en particular, dos sentimentos de familiaridade e da empatía que están na orixe desta publicación puntual, e alén de que o desenvolvemento das hipóteses que aquí se formulen vai estar baseado na materia dese libro e na experiencia da súa xestación, o que me propoño nesta ocasión é dar conta dun exercicio de investigación e escritura que non ten aínda estatuto dabondo recoñecido na súa complexidade, que pode ser disputado, á súa vez, por distintas disciplinas científicas, e que considero que necesita 
repensarse porque, de botarse de lado, está o risco de ignorar materiais valiosos e mesmo fontes para outras investigacións.

\section{2. "Permiso de existencia" ou eses libros que se queren facer un lugar}

Hai unha especie de zona gris, incómoda para o ámbito dos estudos académicos, que é o das memorias individuais. Cómpre recoñecer, no eido dos estudos literarios, a existencia dunha serie de libros que adoitan aparecer 'no patio de atrás' da literatura, que teñen os seus quince minutos de gloria nunha presentación que, no mellor dos casos, se nutre do agarimoso acompañamento de familiares e amizades; pero que, á hora de pasar a ocupar outros espazos, entrar en bibliotecas, ser considerados para algún tipo de estudo dun estado de cuestións que poidan botar luz sobre problemáticas que vaian máis alá dun caso concreto, quedan esquecidos. Moitas veces, o que prevalece é un prexuízo, porque hai libros botados de lado sen que houbese lectura deles. Outras tantas, trátase dun xuízo de valor amparado, non sen atendibles razóns, en cuestións estéticas. Parece estar na base disto - tanto do prexuízo como do xuízoo concepto de que todos temos algo que contar, pero que non sempre se xustifica para iso facer un libro. De haber algo para contar, non ten por que haber necesariamente a necesidade de escribir. Con frecuencia asóciase a expresión dunha historia de vida coa catarse e a realización persoal, e eses libros asoman como pedindo permiso de existencia. Ás veces, os seus propios autores agasallan o froito da súa expresión cunha mestura de vergoña e ilusión que pode mesmo atoparse coa condescendencia de quen o recibe, nun xesto nada prometedor no relativo á posibilidade de que o libro siga o seu camiño. Nunha época na que volveu instalarse a posta en xogo da primeira persoa singular con subliñada presenza nunha escritura que atravesa episodios persoais para dar cabida a realidades máis amplas e complexas -e co sustento que outorga unha xa voluminosa e sólida traxectoria teórica no oficio e no xénero dos testemuños e da súa capitalización a carón da Historia-, é tempo de que a literatura e os profesionais dela acometan (acometamos) a tarefa do diálogo con eses libros, e é tempo tamén de facer parte deles.
O material obxecto de análise co que eu traballei, especificamente, comprende a narración en lingua galega dunha historia en principio persoal e familiar que involucra un marco ilustrativo de avatares políticos fundamentais de Galicia e de Arxentina ao longo de gran parte do século $\mathrm{XX}$, así como tamén aspectos de procesos migratorios e experiencias de represión e cárcere que se poden recoñecer noutras latitudes. Vou facer referencia ás operacións de transposición en libro dos referidos soportes e as bases teóricas que tiven en consideración no proceso.

Debo dicir que a mirada ao lonxe, a perspectiva austral dun enfoque literario que tivo conta dos estudos sobre a memoria e o testemuño para encarar as decisións que requiría a edición dun relato oral, xa desgravado pero que necesitaba ser cotexado todo o tempo coa voz gravada, foi conversada inicialmente en castelán e, para máis precisión, cun acento ben rioplatense. Considerouse nalgún intre a posibilidade de que os textos introdutorios que acompañasen as diversas pasaxes do relato de David estivesen en castelán, ou castelán rioplatense, para mostrar ese fluír entre as dúas terras, as diferentes xeracións e nacionalidades, e as dúas linguas. Porén, foise dando de xeito nada forzado -alén dalgunhas complicacións coa lingua galega- que tamén esas instancias que acompañan a narración en si, estiveran en galego, en consonancia coa lingua que utilizara David para percorrer nun exercicio de memoria a súa vida (veciñal, familiar, política, laboral, social, entre outros campos).

O que segue, que nalgún modo, como declaro en nota a rodapé, tamén deixo expresado no estudo introdutorio, fai parte do itinerario e dos factores que se atopan baixo e tras o traballo de memoria que aspirou a estar o máis preto posible da persoa que o inspirou e dos que foron en busca das súas palabras.

\section{As operacións de transposición e o xiro sub- xectivo $^{3}$}

Nos últimos anos -con máis intensidade na última década e media- ocorreu que en diversas disciplinas vencelladas coas Humanidades e as Ciencias Sociais houbo un retorno ao interese por abordaxes centradas no suxeito. Malia que cada decisión que inclúa o tratamento textual 
da palabra dunha persoa sobre episodios vitais que selecciona para o seu relato ten particularidades, os antecedentes en materia de testemuño oral e a herdanza de máis de trinta anos nos que as teorías sobre o testemuño tiveron un importante desenvolvemento brindan un feixe de ideas, de posicións metodolóxicas e tamén de dificultades ou, polo menos, de coidados. A edición da oralidade non constitúe, por suposto, unha novidade nin algo privativo dunha ou doutra latitude. Para min foi especialmente iluminador, hai xa anos, o proceso de edición que tivo como figura clave a líder guatemalteca Rigoberta Menchú como caso paradigmático que deu lugar a numerosas reflexións sobre os alcances e problemáticas no xesto de incorporar nunha difusión en libro a voz de alguén que narra (e confía e dalgún xeito entrega) parte da súa vida. A publicación, nos anos 80, de Me llamo Rigoberta Menchú y así me nació la conciencia, a cargo de Elizabeth Burgos, e os intercambios de perspectivas que axiña viñeron continúan sendo interesantes para tomar dimensión do importante que é tentar un ton e unhas condicións de reprodución que respecten a exposición narrativa daquel que conta a súa historia. Que a respecten e que, dalgún xeito, se poñan ao seu dispor. Se ese libro de e sobre Rigoberta Menchú -e o uso dobre de preposicións é intencionado... De quen é o libro? De Burgos? De Rigoberta? É só sobre a líder guatemalteca?-, matriz para os estudos sobre o testemuño, trouxo as controversias que trouxo, foi, en esencia, pola decantación da asimetría entre os roles das dúas mulleres. Moi dificilmente poderiamos sintetizar aquí a problemática, pero intentarémolo polo menos en función do que resulte necesario nestas páxinas. Alguén dunha cultura central, con parámetros, ferramentas e motivacións diferentes das da persoa que brinda testemuño é quen administra os recursos e os resultados dun intercambio que verbalmente entrega a vivencia dunha historia marcada por un sufrimento atávico de exclusións e opresións. Nun primeiro momento parece primar o encontro de miradas, a suma de voces e, sobre todo, o lugar dado á voz que dá testemuño. É ben certo que, no comezo, a lóxica que vai contra o que o sistema pide significa un ar de sa transformación no eido da academia. Tal como lembra Stanley sobre ese caso paradigmático:
[D]urante a época de Reagan e Bush, a nova dereita norteamericana fixo de Me llamo Rigoberta Menchú, ou máis exactamente da súa versión en inglés, I, Rigoberta Menchú, an indian woman in Guatemala, un dos obxectivos do seu ataque contra o multiculturalismo no que chamaba, nunha especie de macarthysmo á inversa, political correctness (o concepto remite á ortodoxia supostamente imposta na universidade norteamericana por profesores marxistas e feministas, a crítica anti-colonialista e anti-racista, a deconstrución, etcétera). O testemuño de Rigoberta Menchú foi seleccionado pola prestixiosa Universidade de Stanford para un dos cursos subgraduados obrigatorios de introdución á cultura occidental, despois dun debate no que interveu, contra a decisión da maioría da facultade, William Bennett, daquela Secretario de Educación da administración Reagan. (Beverley 1993: 486) ${ }^{4}$

Pero axiña van vir as posturas encontradas e, o máis grave, a complexa apropiación dunha materia narrativa que pasa a ser unha sorte de mercancía académica capaz de erosionar a textura da súa articulación orixinaria. Un problema de base é a presunción dunha harmonía intanxible, idílica, que fraco favor lle fai á complexidade de factores inseridos na lóxica testemuñal. Ao considerar o que observa como un exemplo (Hasta no verte, Jesús mío, de Elena Poniatowska) que contempla a multiplicidade que intervén nestes casos, Dröscher sostén:

[N]on se trata dun monólogo senón dun diálogo. Pódese dicir, ademais, que se abre un espazo discursivo, polo menos, entre tres puntos: a informante, a editora, e o lector ou a lectora. Finalmente, o texto revélase como unha polifonía, xa que é realmente capaz de integrar voces marxinalizadas ao campo literario. (2001: s.p.)

E localiza, como contraexemplo, a inviable disposición monocroma á que aspirou Burgos na súa experiencia con Rigoberta Menchú:

O contrario sucede co testemuño Me llamo Rigoberta Menchú y así me creció [sic] la conciencia. Suprimir rupturas, harmonizar diferencias e disimular a propia posición como editora foi o método explícito de Elizabeth Burgos. Disimular a posición da editora ao poñerse como simple transcritora do relato oral, a falta de autorreflexión e o xesto realista (no sentido da literatura do realismo), todo iso fai deste testemuño un documento sumamente vulnerable á crítica. (Ibid.: s.p.)

4 Esta e todas as traducións das citas da bibliografía teórica son miñas. 
Non imos entrar agora niso con detalle, pero a disputa que sobreveu entre Elizabeth Burgos e Rigoberta Menchú sobre, por exemplo, os corolarios que tivo a publicación (Dröscher 2001) e o xeito de cuestionar o texto por parte de David Stoll, aludindo a que a narrativa non replicaba o que as testemuñas que el entrevistou contaron dos feitos referidos no libro (1999), como outro punto de inflexión, fan ver que o cara a cara desta práctica narrativa está lonxe de constituírse nun intercambio transparente e inocuo. Ocorre que a asimetría primixenia non é nada doado de saltear, mesmo no caso de que o investigador, o editor -o "facedor", en síntese- tivese a mellor das intencións, que non sempre é o que ocorre.

As esixencias e os mandatos formais das institucións onde se xestan investigacións que funcionan como vehículo de expresións de suxeitos que tiveron vedado o acceso a proferir a súa historia dun xeito visible e central -ou que polo menos o tiveron difícil- responden a lóxicas institucionais que levan en si unha estratificación á que estamos afeitos, malia que cada tanto a queiramos 'deconstruír' para sacudirnos prexuízos verticais.

Agora ben, o problema está xustamente en que se anquilosou unha modalidade de relación entre entrevistador e testemuña que non deixou de ser asimétrica e de deter o informante nun rol supeditado ao visto bo alleo -isto vén pasando desde hai décadas, desde os comezos da literatura testemuñal e a historia oral, e aínda algunhas prácticas actuais non deixan moita marxe para realizar un xiro radical e facer que o suxeito que relata se converta dunha boa vez no verdadeiro protagonista. Só desa maneira vai ser posible a universalización do seu discurso. Malia que pareza paradoxal, a relativa autonomía que isto implicaría é quen de abrir o xogo para outros protagonistas. Non lle podemos botar a culpa aos historiadores que de moi boa fe deron impulso á Historia Oral, atoparon con moito sacrificio espazos para facer ouvir esas voces 'outras' e loitaron contra as miradas desconfiadas dos seus propios lugares de pertenza. Pero alí está a cuña que pode interpoñer a literatura, que guinda pola borda a compresión dun intercambio bilateral conducido por unha voz 'autorizada', a do profesional, para calibrar a presenza, o ton e os silencios da outra voz imprescindible, a primeira, a das vivencias que se transmiten. Entón temos que falar dun movemento dobre: por unha banda, como ocorre coa teoría da transposición cinematográfica que, en detrimento do concepto de 'adaptación', non sostén que unha linguaxe estea en función da outra (para ese caso, un filme en función de adaptación dun texto literario), senón que se trata de materialidades expresivas diferentes, cada unha cos seus propios elementos, pezas e ferramentas. Nese xiro fai falta tamén repensar, como se repensou dende a didáctica e a pedagoxía a relación ensino-aprendizaxe, os roles que interveñen nese intercambio. O que ocorreu coas entrevistas levadas adiante por Antón Santamarina e familia con David Álvarez Carballido foi que verdadeiramente o obxectivo que guiaba o proxecto era facer coñecer a historia, sen concomitancias académicas, profesionais, laborais que puidesen estorbar as decisións estruturais das entrevistas. Isto non quere dicir en modo ningún que teñamos que estar en contra de que un proxecto como este veña amparado polo impulso dun orzamento que permita que non durma na gloria do descoñecemento impoluto. Non se pode ter tanta inxenuidade. Tampouco quere dicir que o coidado filolóxico non estivese sempre presente, como unha marca profesional xa inseparable da persoa que a adquiriu. Pero hai que recoñecer que cando hai factores que contribúen a que as motivacións 'foráneas' se reduzan ao mínimo, ou mesmo que desaparezan, o resultado é moito máis amable, e tamén máis verosímil, o que de feito podería redundar, nunha sorte de 'círculo virtuoso', en mellores resultados cara ao institucional, que a fin de contas é o noso medio de adopción. Esas condicións favorables déronse con tanta intensidade no exemplo do libro ao que aquí nos referimos que non fixo falta adelgazar a tentadora e perigosa condición estelar que adoitan ter algúns entrevistadores que, mesmo contra a súa vontade, fan gala dunha condescendencia que necesariamente obtura a expresión da testemuña na súa máxima liberdade.

En relación con isto, cabe lembrar que hai unha tripartición que identifica Álvaro Kaempfer para os "prólogos testemuñais":

Os prólogos posúen neles unha relación co relato testemuñal organizada en tres momentos. $\mathrm{O}$ primeiro remite á lexitimación persoal, vital e profesional do proxecto testemuñal. O segundo organiza a colonización interna do "Outro" de acordo cos parámetros do primeiro momento, a que xorde como un proceso de obxectivación, subordinación e inclusión dese Outro. O terceiro localiza o testemuño dentro dun proxecto maior onde a narrativa testemuñal alcanza a súa lexitimación. (2000: s.p.)

Isto, que conforma un esqueleto aplicable á maioría, desarticúlase no prólogo de Antón Santamarina, o entrevistador de Álvarez 
Carballido, que configura o seu rol na liña dunha posta ao servizo do suxeito "outro" e do obxecto-obxectivo da súa palabra. E non se trata en absoluto dunha falsa humildade nin dun tópico de captatio benevolentiae. Hai unha inversión respecto do que se considera o rol coñecedor, experto, e un xesto de baleirar a dinámica xustificativa propia destas instancias paratextuais. Sempre hai construción nesta serie de roles. Iso non ten nada malo, por suposto; a cuestión é que aquí se constrúe moi claramente para destacar a relevancia do outro.

Cando eu nacín (1942) David Álvarez tiña 20 anos. Seis anos despois (1948) deixou a aldea para irse a Bos Aires, así é que a miña memoria del nesa época é borrosa. Cando volveu (1962) xa era eu un estudante en Santiago. (...) Non sei se algunha vez tivo a pretensión de facerme militante do Partido Comunista (PC). El nunca mo propuxo nin eu llo pedín. Sospeitei que as non poucas visitas que me facía un tal Ramón (...) eran para intentar seducirme para a causa. Non estiven á altura do que esperaban e supoño que os decepcionei (...). Con todo nunca estiven nas antípodas deles e en moitas ocasións fun compañeiro de viaxe consciente. (Almasia e Sánchez 2018: 19)

Deste xeito instala tamén a cuestión da política partidaria que, por unha banda, non é menor, xa que as conviccións de Álvarez Carballido dan conta desa adscrición mesmo desde antes da súa afiliación; mais patentiza, á súa vez, a universalidade e o carácter transversal de quen é admirado e respectado alén de bandeiras.

Nese mesmo exercicio de autoconstrución responsable de dar a coñecer o que finalmente se materializou moito tempo despois das xuntanzas iniciais, Santamarina bótase a culpa sobre a demora. Nunha actitude acaso demasiado xenerosa, localiza na operación de "rescate" feita vinte anos despois un punto culminante.

$[\mathrm{P}]$ or falta de tempo, fun adiando a tarefa de darlle formato de libro. Aínda que ían pasando os anos David nunca me reprochou o meu quebranto do compromiso; pero a pesar de non ter nunca unha queixa da súa parte sei que estaba doído e eu con mala consciencia por non ter cumprido a miña promesa. Todos os que o coñeceron saben que era un home modesto; o cal non quita que ao mesmo tempo estivese convencido de que o seu ideario era bo e sentise orgullo de que o que tiña feito e padecido valera a pena e merecía ser contado. Era fácil percibir que lle gustaría ter en vida a súa cota de gloria no que foi a loita contra o franquismo mentres durou Franco e mesmo despois de desaparecido. Outros como Paco Balón ou Manuel Barros tiveran un recoñecemento no seu día. (Santamarina 2018: 21-22)

Santamarina chega mesmo a afirmar que David era quen de escribir as súas propias memorias, pero que cría $-\mathrm{o}$ mesmo David, quizais de xeito erróneo, deixa entrever Santamarinaque lle faltaba rigorosidade e disposición para esa tarefa. Como vemos, o prologuista, coidadosamente, cunha pericia equidistante entre a responsabilidade profesional e o coñecemento persoal, delinea o contorno da súa testemuña e cédelle o espazo, reservando para si mesmo calquera posibilidade de crítica.

$\mathrm{Na}$ outra 'intromisión', na que vinte anos máis tarde retoma o traballo de Santamarina ${ }^{5}$, hai outros apoios nos que ampararse. Os estudos que volveron ás características e ás consecuencias desa sorte de "apropiación" dunha voz proferida en determinadas circunstancias que forma o testemuño de alguén máis -e que si ou si vai atravesar algún tipo de transformación ao mudar de soporte- serviron para procurar repor na voz de David Álvarez Carballido feita escrita unha suma de condicións que, ante todo, seguisen a enunciación rexistrada na súa formulación orixinaria. A orde cronolóxica é acaso unha convención que non necesariamente ten que acompañar unha narración autodiexética. Porén, neste caso a verdade é que o propio narrador era dabondo metódico, e algunhas analepses e prolepses -que hai poucas ao longo das once cintas dixitalizadas coas que traballei no cotexo das desgravacións que xa se fixeran- son funcionais á articulación do relato. Só foron botadas de lado algunhas reiteracións, que non eran moitas, e foi seleccionada unha traxectoria que incluíse do xeito máis completo posible os seus primeiros anos de formación, a súa nenez como testemuña das xuntanzas nos seus pagos en San Martín perante a II República, pasando polas lecturas, os primeiros traballos, a

\footnotetext{
Non me deteño aquí no completísimo e pormenorizado prólogo no que, a continuación das "Palabras previas" de Antón Santamarina, redactou Xesús Alonso Montero, xa que non afecta especificamente aos asuntos teóricos dos que tratamos neste caso; pero reenvío a todo lector que queira unha documentada e experta posta en contexto a percorrer os detallados apartados que constitúen esa outra escritura preliminar.
} 
migración a Arxentina, a participación política e social alá, o seu coñecemento de moitos dos protagonistas do exilio español en Bos Aires, as tres detencións que sufriu na outra beira, a volta a Galicia, a experiencia do cárcere en Vigo, o xurdimento do Partido Comunista Galego, entre outros nodos significativos.

Alén das perspectivas e problemáticas teóricas mencionadas e aludidas aquí con algún detalle, hai que engadir que traballos como os de Ana María Amar Sánchez, Miguel Barnet, Álvaro Kaempfer, o Grupo Latinoamericano de Estudos Subalternos e Gayatri Spivak foron fundamentais para o tratamento da materia prima coa que contabamos. Este marco constitúe unha imprescindible bagaxe, pois sen ter sopesado previamente a complexidade dos suxeitos que interveñen, os soportes, as instancias paratextuais e outros aspectos envoltos nos testemuños, sen dúbida sería moito menos detida a exploración de diferentes xeitos de organizar os materiais dos que se dispuña.

Despois do auxe das teorías sobre o testemuño, que tiveron un evidente desenvolvemento nos anos 80 e que están en débeda con achegamentos previos, así como con outras teorías concernentes ao paradigma das "escritas do eu", ocorreu unha gradual desconfianza, manifesta no reparo, no excesivo coidado fronte á idea de que a voz da testemuña teña unha validez per se. Isto dáse sobre todo cando a teoría adopta o concepto de 'xiro lingüístico' para pasar a falar do 'xiro subxectivo' e sinalar criticamente certos aspectos da cultura da memoria. A partir das observacións do libro de Beatriz Sarlo Tiempo pasado. Cultura de la memoria y giro subjetivo. Una discusión, que puxeron en cuestión características esenciais do testemuño e a súa validación, xurdiu un debate que excede a extensión deste traballo, pero que convén ter presente porque se produciu unha disputa teórica que tivo o seu centro na cuestión da veracidade e os alcances da memoria, así como tamén da narración en relación con iso. "Todo testemuño quere ser crido e, porén, non leva en si mesmo as probas polas cales se pode comprobar a súa veracidade, senón que elas deben vir desde fóra" (Sarlo 2007: 47). Afirmación polémica que se intensifica aínda máis cando Sarlo alude aos mecanismos que virían a lexitimar a verdade intrínseca na articulación verbal da propia experiencia:

O testemuño, pola súa autorrepresentación como verdade dun suxeito que relata a súa experiencia, pide non se someter ás regulacións que se aplican a outros discursos de intención referencial, alegando a verdade da experiencia, cando non a do sufrimento, que é a que precisamente necesita ser examinada. (Ibid.: 49)

Pasada a exposición deste problema, Sarlo acusará de "optimismo teórico" aquelas posicións que xunto co que ela nomea como un "deconstrucionismo filosófico "brando"” (Ibid.: 51) se mostran dabondo en débeda cun Suxeito unívoco anterior ao século XX na configuración de Suxeitos Múltiples capaces de proferir as súas verdades. Nesa apelación ao plural observa Sarlo unha presunta facilidade que critica duramente ao atacar calquera vestixio de optimismo teórico que permita concluír que os suxeitos se tornaron cognoscibles.

A palabra viva dos protagonistas, alén da evidente parcialidade que implica un punto de vista, tiña de por si un valor de verdade? Podíase poñer en dúbida iso?

$O$ retorno do suxeito que se presenta cunha significativa aparición de escritos enfocados nunha historia de vida narrada en primeira persoa de singular fíxose notar con intensidade. Trátase dunha necesidade de expresión individual? Ou é unha iniciativa máis ben social que apela a evitar que determinadas historias, dalgún xeito "pequenas", por individuais e por ser ata certo punto anónimas, se perdan para a Historia? Probablemente ambas as dúas vías converxan. Volver visitar o relato dun suxeito que parece ser un nun millón abre posibilidades de indagar en dimensións narrativas que van máis alá dun anecdotario singular.

\section{4. $O$ persoal no colectivo}

Cando a vivencia se refracta sobre un carácter social, xa non se trata da forma na que unha persoa conta 'o seu'. Sen pretensións de representatividade nin de ser portavoz de ninguén, bota luz sobre realidades que o atravesan. E demostra, á súa vez, que non é un máis nun millón.

A palabra de David Álvarez Carballido reúne o persoal e o colectivo, e con Walter Benjamin, podemos dicir que permite observar o desenvolvemento da vivencia -individual, illada- a un plano máis complexo, o da experiencia. Así é que cobra corpo a memoria dunha experiencia rica en compromisos e nun exercicio da coherencia que atravesa desde as prácticas máis cotiás ata a participación en causas forxadas sobre a base de grandes soños e de aínda maiores expectativas. Ás veces, trátase de grandes historias que afectan realidades de 
índole nacional ou de alcance máis amplo en boca de relatos curtos e sinxelos. Noutras ocasións, transmítense pequenas historias de aparencia inocua pero esenciais para comprender o todo, para ver actuar ao suxeito individual nas súas diversas áreas de desempeño.

Traballar sobre a voz do 'outro', replicada polas sucesivas horas de escoita dos soportes tecnolóxicos que a continúan facendo viable, trae consigo sempre a certeza de que hai algo orixinario que se nos volveu inaccesible. Nesta liña, é inevitable pensar de novo en Walter Benjamin e o seu clásico traballo "La obra de arte en la época de la reproductibilidad técnica" (1973 [1935]), ao botar de menos, nós tamén, unha sorte de dimensión de aura xa irrecuperable, a deses momentos idos nos que un contexto de confianza e coñecemento favoreceu que o relato andase. Pero asumir esa limitación constitutiva que implica o salto á posta por escrito -e máis aínda a súa necesaria edición- habilita tamén un vínculo co oral que se vai afondando e gañando en versatilidade.

Á súa vez, a condición de alteridade que neste caso cabe considerar é relativa, xa que o móbil de dar a coñecer as palabras dunha testemuña e protagonista de instancias históricas do século $\mathrm{XX}$, a un lado e outro do Atlántico, xorde do interese de familiares e amigos de David. A condición de veciño, o carácter familiar, o afecto, en fin, que se desprenden tanto das preguntas que guían as entrevistas das que sae o libro canto da iniciativa de actualizar os textos desgravados atenúan os sinais de alerta por temor a estar indo a contramarcha dalgunha vontade da testemuña e suaviza as precaucións que requiriría outro tipo de proxecto.

Hai que dicir que contabamos con moi boas gravacións e coidadosas transcricións das entrevistas feitas hai dúas décadas. As preguntas do entrevistador non foron inseridas no texto publicado pero estas constitúen, sen dúbida, unha imprescindible - malia que neste caso invisible- estrutura, así como é inaudible a voz. Máis aínda, ao contexto de realización das entrevistas, nas que se percibe un ambiente de intimidade e empatía que facilita o desenvolvemento dos temas, súmase, como se anticipou, a presenza doutras voces familiares que coadxuvan para algunhas reformulacións e para contribuír, ás veces, á recuperación de datos puntuais.

A memoria individual de David tórnase en moitas pasaxes coral. Nalgunhas notas a rodapé facemos referencia a comentarios do entrevistador e a ampliacións dalgunha índole. Estes apuntamentos, malia que non reviven ese clima favorecedor, representan polo menos unha mostra dunhas condicións de posibilidade valiosas e necesarias para lle dar á testemuña o rol principal.

Á hora de editar o texto, entón, decidiuse incorporar só a voz de David. Constrúese o seu relato como unha narración fluída subdividida polo medio de subtítulos separadores que van encadeando temas, nomes e episodios; pero está claro que opera por detrás o labor de Antón Santamarina no mellor desempeño que pode ter un entrevistador: o de facer preguntas intelixentes de modo sensible e informado, o de evitar un lucimento persoal que poida ir en detrimento da posición central da palabra do entrevistado, o de proceder case de xeito tanxencial pero de modo decisivo para apuntalar o desenvolvemento do discurso.

Cada apartado reúne varios núcleos do relato e está encabezado por un texto introdutorio que procura anticipar aspectos centrais da sección descritiva. Tanto os títulos e os subtítulos como os resumos para anticipar contidos son agregados que interveñen na narración pero que tamén entran en diálogo con ela. Moitos fragmentos teñen unha extensión semellante entre si. Isto débese a que a propia testemuña contribuíu moito, mediante focos de atención parella, regular, a que cada referencia a un tema ou a unha persoa tivese o seu espazo; pero hai tamén algunhas pasaxes notoriamente breves que é mellor deixar porque operan fugaces asomos de memoria a través dos cales David lembra alguén a quen non quere deixar no esquecemento; entón incorpórase a referencia, ás veces moi efémera.

Non penso que agora caiba máis que falar e recordar aos que ides quedar como depositarios desta vivencia que vos conto, que non é con ningún ánimo persoal meu de figurar, é soamente para que se coñeza mellor a historia. E malia que hoxe non traio máis nomes anotados, lembro que estiven ligado a todos os cataláns, como Rocamora, como Juan Cuatrecasas, que eran catedráticos de Medicina. No ano 90 aínda estiven con Rocamora no Casal de Cataluña. (Almasia e Sánchez 2018: 245)

Certas reiteracións foron editadas. Suprimíronse, por exemplo, pasaxes nas que se mencionaba unha anécdota pola segunda vez. Porén, dado que David, cando volvía sobre algún tema, facíao de xeito consciente, para completar algún dato que non estaba na versión previa, 
consideramos eses xestos de enriquecemento da narración e, nalgunha ocasión, esas pezas fusionaron e complementaron os elementos das distintas versións.

Outros silencios polos que optamos responden a moi diferentes motivos: ocorre especialmente na primeira parte - a que remite a episodios localizados en Galicia e máis precisamente na aldea-coa inclusión das iniciais no lugar do nome completo no caso da acción dalgunhas persoas. Nesta decisión de recorte é claro o obxectivo de non causar incomodidade nos familiares de suxeitos que tiveron unha participación afín á sublevación contra a II República e que foron designados como responsables de accións de persecución e de delación perante a guerra e o franquismo.

Pero o silencio máis radical vén dado polo feito de non poder contar coa última posibilidade de completar detalles da man do propio David, xa que a súa saúde se deteriorou na última etapa do proxecto. Morreu moi pouco antes de que as últimas instancias deste traballo que veño describindo tivese a súa forma definitiva. A prodixiosa memoria que tiña e a súa capacidade para organizar o relato, o rexistro de pormenores e a súa pericia observadora fan que non sexan moitas as lagoas nin irrecuperables certos esquecementos.

Polo contrario, poden funcionar como unha invitación de diálogo para continuar unha historia, que neste caso que expoño é a de David, pero que pode convocar a outras voces. Finalmente, cómpre lembrar, como el mesmo manifestou hai vinte anos ao se referir ao obxectivo de máxima que o impulsaba a falar, o seguinte:

O que eu digo aquí é soamente para que non quede esquecido. Todo o que sabemos do franquismo, todo o que sabemos daquel terror que invadiu España, que se coñeza. Agora, por exemplo, están vindo unhas xeracións que teñen interese en saber e que son especialmente intelectuais. (...) E iso é o que eu desexaba, ou sexa, antes de morrer, que queden estes datos. Para iso é. Non me importa o meu nome. Impórtame tres pitos o que digan ou non digan. Fun unha persoa máis, unha persoa sen coñecementos. (Almasia e Sánchez 2018: 378-379)

Esa falta de coñecemento á que alude coa excesiva humildade que caracterizou a David só dá conta do plano da educación formal e ten a súa contrapartida na admirable memoria dunha vasta e auténtica experiencia, un bo antídoto para outras xeracións e ante outros (ou os mesmos e reciclados) terrores.

Para a articulación de certas verdades xa é tarde. Moitos morreron sen falar, outros tantos sen seren ouvidos. $\mathrm{O}$ bo é que temos máis ferramentas -teóricas sobre o testemuño, sobre as voces presuntamente 'menores' ou 'satelitais' da Historia, sobre procesos literarios de 'verosimilización' - respecto de hai non tantos anos para facer lexible (e indirectamente audible), co amparo da condición narrativa que a torne viable, a recuperación dalgunhas desas voces que están agardando erguer a cabeza desde certos letargos tinxidos de agravantes conxunturais.

\section{Referencias bibliográficas}

Almasia, Anahí e Mariela Sánchez (eds.) (2018): Memorias dun loitador antifranquista. O testemuño do comunista David Álvarez Carballido. Santiago de Compostela: Alvarellos.

Alonso Montero, Xesús (2018): "Memorias dun loitador antifranquista case anónimo: o comunista David Álvarez Carballido (1922-2017)", en A. Almasia e M. Sánchez (eds.), Memorias dun loitador antifranquista. O testemuño do comunista David Álvarez Carballido. Santiago de Compostela: Alvarellos, pp. 25-47.

Amar Sánchez, Ana María (1992): El relato de los hechos. Rodolfo Walsh: testimonio y escritura. Rosario: Beatriz Viterbo.

Barnet, Miguel (1991 [1971]): "La novela-testimonio: socioliteratura", en N. Klahn e W. Corral (comps.), Los novelistas como críticos. México: Fondo de Cultura Económica.

Benjamin, Walter (1972 [1939]): "Sobre algunos temas en Baudelaire”, en Poesía y capitalismo. Iluminaciones II (trad. Jesús Aguirre). Madrid: Taurus, pp. 123-170.

(1973 [1935]): “La obra de arte en la época de la reproductibilidad técnica", en Discursos interrumpidos I (trad. Jesús Aguirre). Madrid: Taurus, pp. 17-59.

_- (1986 [1936]): “El narrador”, en Sobre el programa de la filosofía futura (trad. Roberto Vernengo). Barcelona: Planeta-Agostini, pp. 189-212.

Beverley, John (1993): "El testimonio en la encrucijada", Revista Iberoamericana 59/164-165, pp. 485495, DOI: https://doi.org/10.5195/reviberoamer.1993.5169. 
Burgos, Elizabeth (1983): Me llamo Rigoberta Menchú y así me nació la conciencia. La Habana: Casa de las Américas.

Dröscher, Barbara (2001): “El testimonio y los intelectuales en el triángulo atlántico. Desde El Cimarrón, traducido por H. M. Enzensberger, hasta la polémica actual en torno a Rigoberta Menchú, de Elizabeth Burgos", Istmo 2, http://istmo.denison.edu/n02/articulos/intel.html.

Grupo Latinoamericano de Estudios Subalternos (1998): "Manifiesto inaugural", en S. Castro-Gómez, Santiago e E. Mendieta (eds.), Teorías sin disciplina (latinoamericanismo, poscolonialidad y globalización en debate). México: Porrúa.

Kaempfer, Alvaro (2000): "Los prólogos testimoniales: paratextos, otredad y colonización textual”, Estudios Filológicos 35, pp. 191-206, DOI: http://dx.doi.org/10.4067/S0071-17132000003500013.

Sánchez, Mariela (2018): "Editar la oralidad. Algunas bases teóricas y otras consideraciones en torno a la narración de una historia de vida", en A. Almasia e M. Sánchez (eds.), Memorias dun loitador antifranquista. O testemuño do comunista David Álvarez Carballido. Santiago de Compostela: Alvarellos, pp. 49-57.

Santamarina, Antón (1999): "De como e con quen o profesor se meteu en política. Anacos das memorias de David Álvarez Carballido", en R. Álvarez Blanco e D. Vilavedra (1999); Cinguidos por unha arela común: homenaxe ó profesor Xesús Alonso Montero. Santiago de Compostela: Universidade de Santiago de Compostela, pp. 153-171.

(2018): "Palabras previas", en A. Almasia e M. Sánchez (eds.), Memorias dun loitador antifranquista. O testemuño do comunista David Álvarez Carballido. Santiago de Compostela: Alvarellos, pp. 19-23.

Sarlo, Beatriz (2007 [2005]): Tiempo pasado. Cultura de la memoria y giro subjetivo. Una discusión. Buenos Aires: Siglo veintiuno editores.

Spivak, Gayatri (1988): “Can the subaltern speak?”, en C. Nelson e L. Grossberg (eds.), Marxism and the interpretation of culture. Urbana: University of Illinois Press, pp. 271-313.

Stoll, David (1999): Rigoberta Menchú and the story of all poors guatemalans. Colorado: Westview Press. 